\title{
Effect of UV-Irradiation on Polyelectrolyte Multilayered Films and Hollow Capsules Fabricated via Layer-by-Layer Assembly
}

\author{
Kiyofumi Katagiri, ${ }^{*}{ }^{\dagger}, \uparrow$ Atsunori Matsuda ${ }^{\dagger}$ and Frank Caruso ${ }^{\ddagger}$ \\ Department of Materials Science, Toyohashi University of Technology, Toyohashi, Aichi 441-8580, \\ Japan, Centre for Nanoscience and Nanotechnology, Department of Chemical and Biomolecular \\ Engineering, The University of Melbourne, Victoria 3010, Australia.
}

* To whom correspondence should be addressed. E-mail: katagiri@apchem.nagoya-u.ac.jp

${ }^{\dagger}$ Toyohashi University of Technology.

$\$$ The University of Melbourne.

I Present address: Graduate School of Engineering, Nagoya University, Nagoya 464-8603, Japan. 


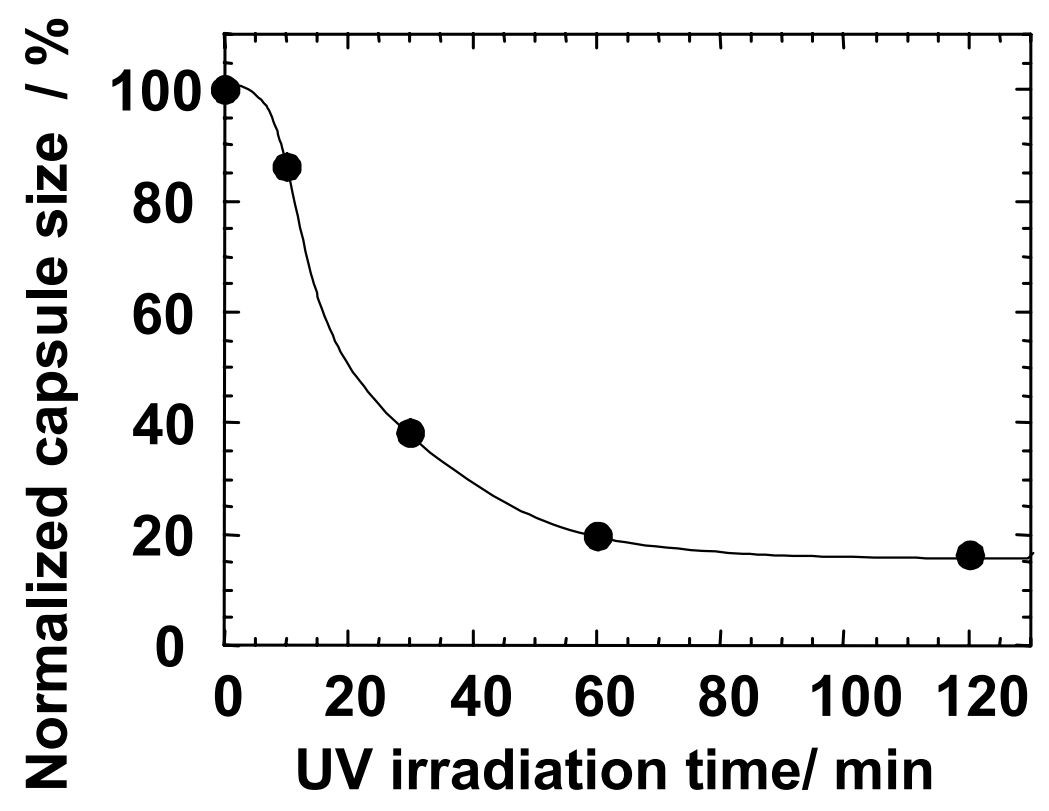

Figure S1. Shrinkage of (PSS/PDDA) 5 /PSS polyelectrolyte capsules fabricated with $3.05 \mu \mathrm{m}$ MF cores: average diameter of capsules as a function of UV irradiation time with irradiation of $20 \mathrm{~mW} \mathrm{~cm}^{-2}$. 


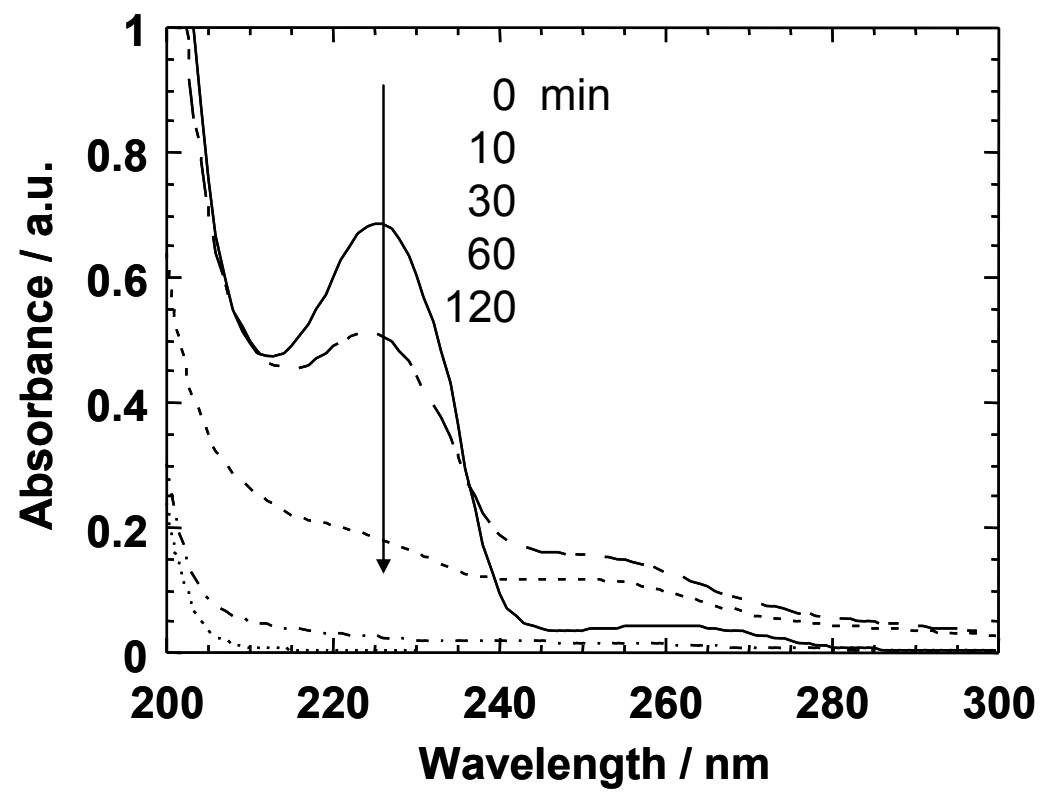

Figure S2. UV-vis absorption spectra of PSS in solution with UV irradiation at $20 \mathrm{~mW} \mathrm{~cm}{ }^{-2}$ for 0,10 , 30,60 , and $120 \mathrm{~min}$.

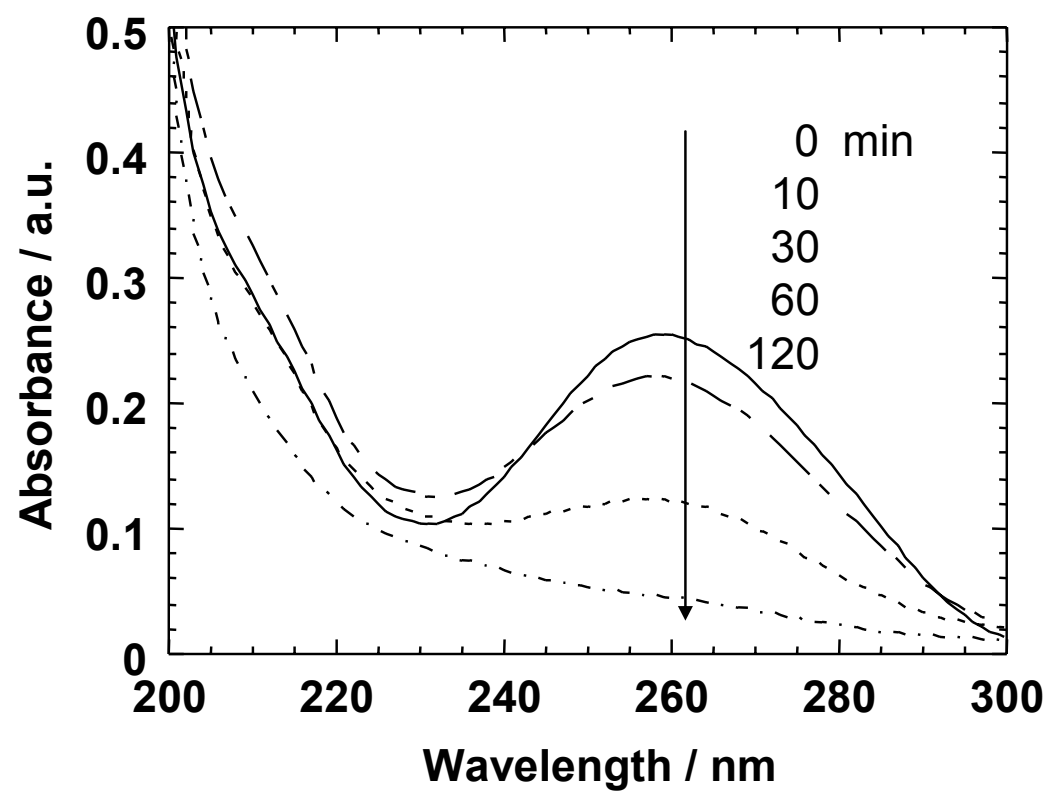

Figure S3. UV-vis absorption spectra of DNA in solution with UV irradiation at $20 \mathrm{~mW} \mathrm{~cm}^{-2}$ for 0,10 , 30,60 , and $120 \mathrm{~min}$. 


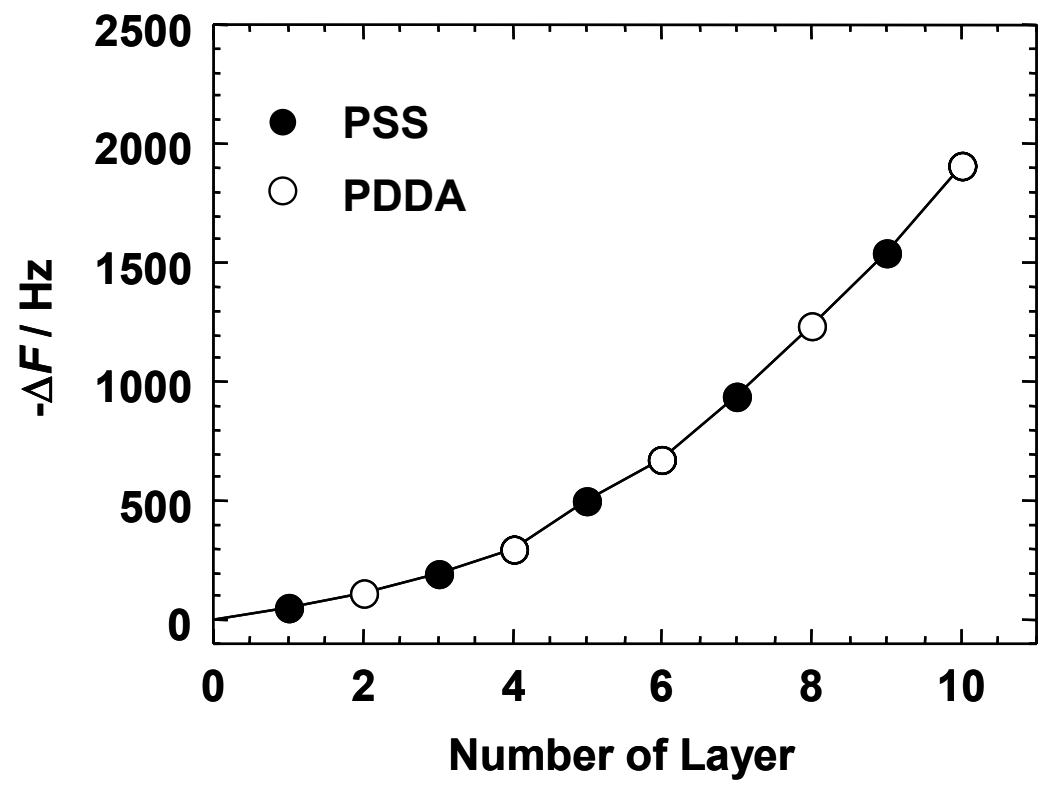

Figure S4. QCM frequency decrease $(-\Delta F)$ for the alternate layer-by-layer deposition of PSS/PDDA. Closed circles: PSS (1.0 mg mL $\mathrm{mL}^{-1}$ in $\left.0.5 \mathrm{M} \mathrm{NaCl}\right)$; open circles: PDDA $\left(1.0 \mathrm{mg} \mathrm{mL}^{-1}\right.$ in $\left.0.5 \mathrm{M} \mathrm{NaCl}\right)$ QCM frequencies were recorded in air.

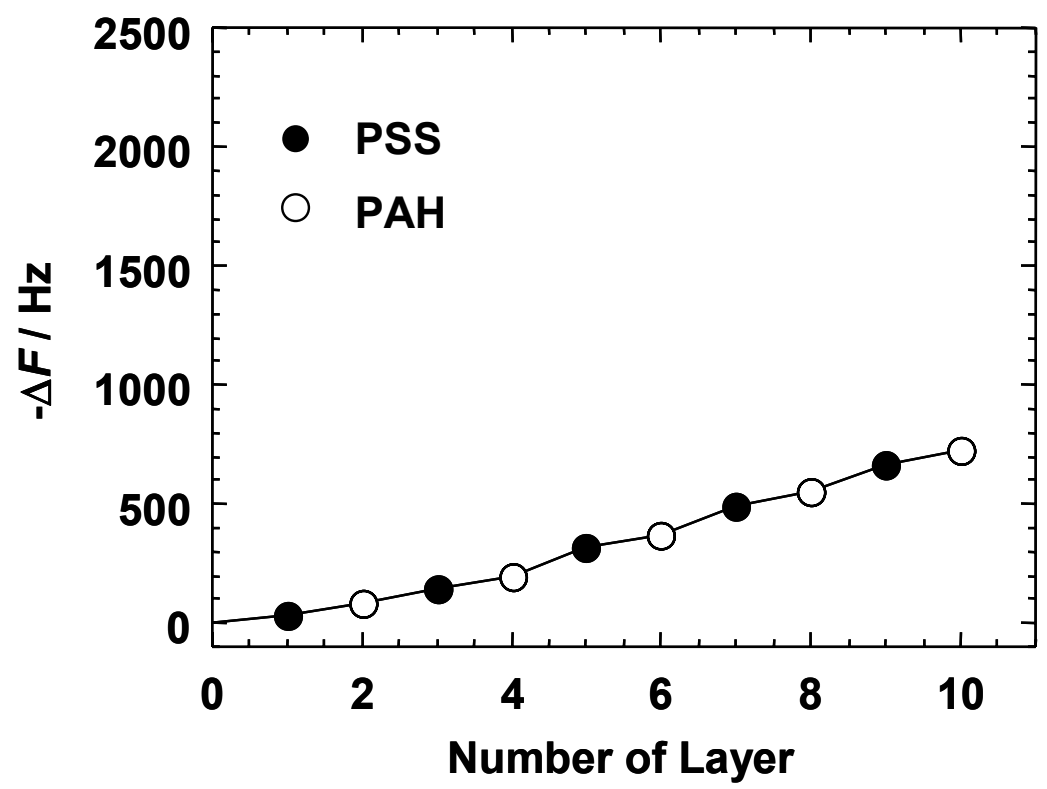

Figure S5. QCM frequency decrease $(-\Delta F)$ for the alternate layer-by-layer deposition of PSS/PAH. Closed circles: PSS $\left(1.0 \mathrm{mg} \mathrm{mL}^{-1}\right.$ in $\left.0.5 \mathrm{M} \mathrm{NaCl}\right)$; open circles: PAH $\left(1.0 \mathrm{mg} \mathrm{mL}^{-1}\right.$ in $\left.0.5 \mathrm{M} \mathrm{NaCl}\right)$ QCM frequencies were recorded in air. 


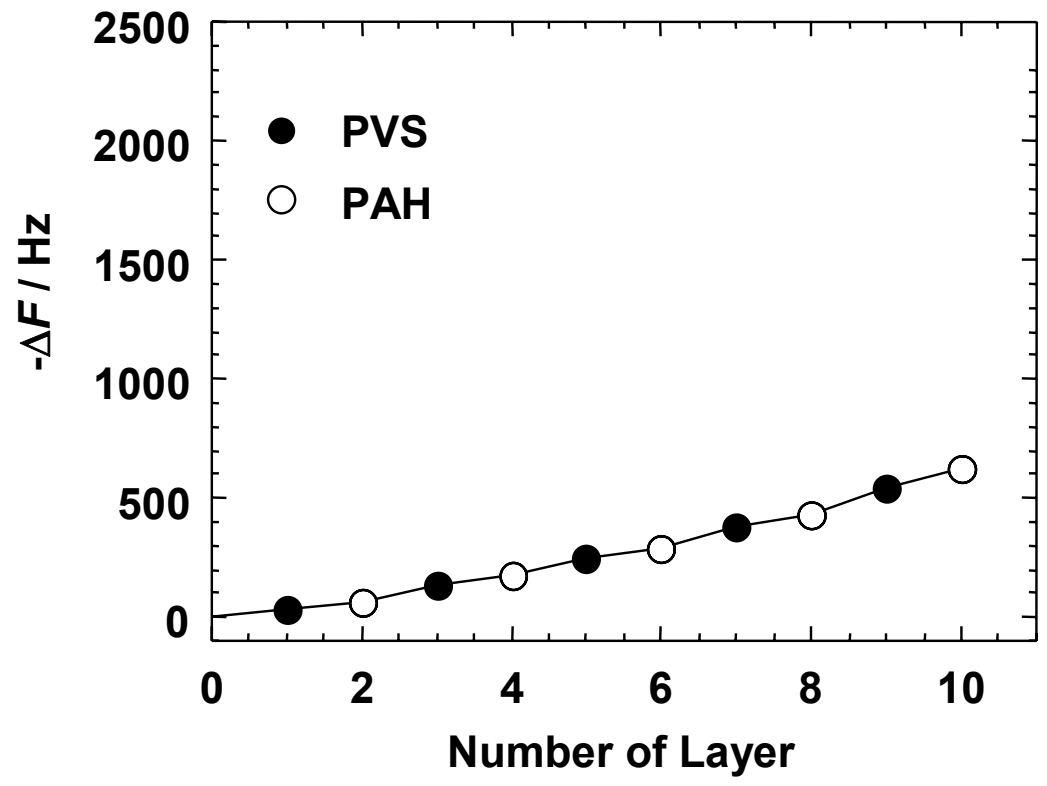

Figure S6. QCM frequency decrease $(-\Delta F)$ for the alternate layer-by-layer deposition of PVS/PAH. Closed circles: PVS $\left(1.0 \mathrm{mg} \mathrm{mL}^{-1}\right.$ in $\left.0.5 \mathrm{M} \mathrm{NaCl}\right)$; open circles: PAH $\left(1.0 \mathrm{mg} \mathrm{mL}^{-1}\right.$ in $\left.0.5 \mathrm{M} \mathrm{NaCl}\right)$ QCM frequencies were recorded in air.

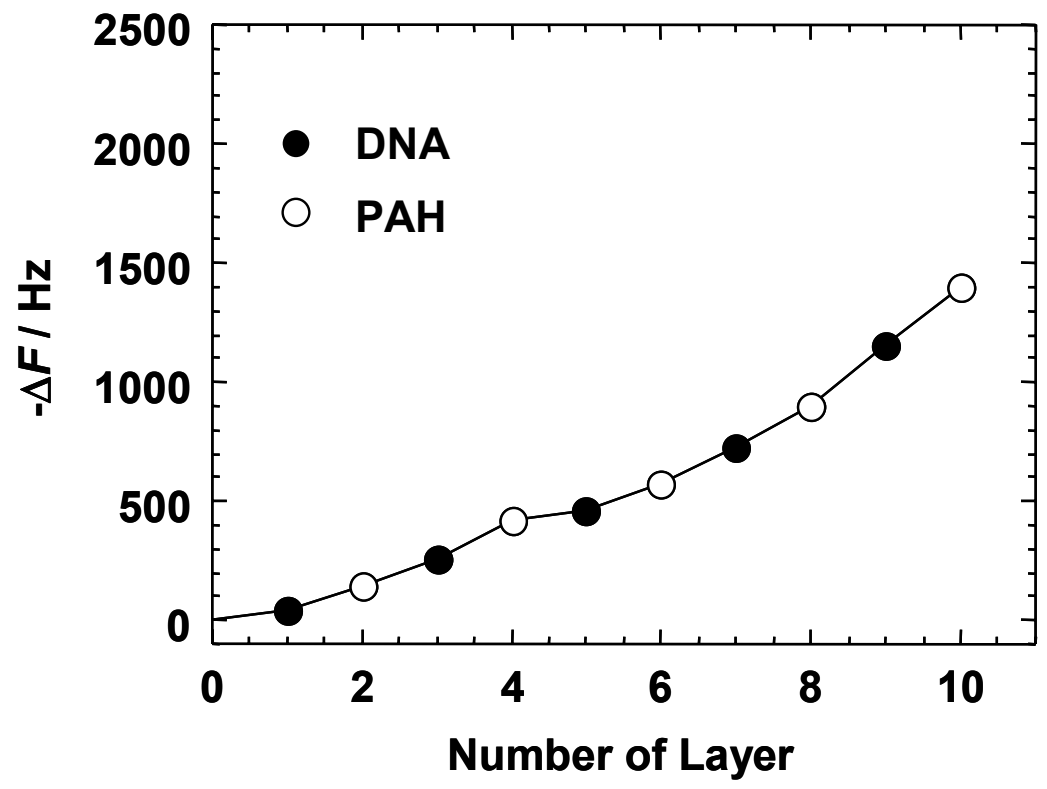

Figure S7. QCM frequency decrease $(-\Delta F)$ for the alternate layer-by-layer deposition of DNA/PAH. Closed circles: DNA $\left(1.0 \mathrm{mg} \mathrm{mL}^{-1}\right.$ in $\left.0.5 \mathrm{M} \mathrm{NaCl}\right)$; open circles: PAH $\left(1.0 \mathrm{mg} \mathrm{mL}^{-1}\right.$ in $\left.0.5 \mathrm{M} \mathrm{NaCl}\right)$ QCM frequencies were recorded in air. 